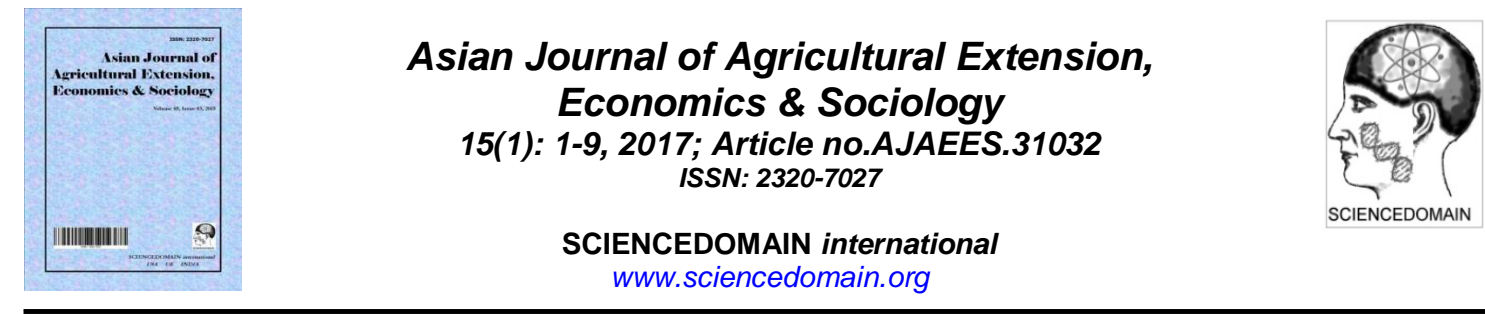

\title{
Dynamics in Theeramythri Activity Groups: Analysing Coherence among the Group Members
}

\author{
Shyam S. Salim ${ }^{1 *}$, N. R. Athira ${ }^{1}$ and Reeja Fernandez ${ }^{1}$ \\ ${ }^{1}$ Socio Economic Evaluation and Technology Transfer Division, Central Marine Fisheries Research \\ Institute, Kochi, Kerala, Pin-682018, India.
}

Authors' contributions

This work was carried out in collaboration between all the authors. All authors read and approved the final manuscript.

Article Information

DOI: $10.9734 / A J A E E S / 2017 / 31032$

Editor(s):

(1) Angel Paniagua Mazorra, Centre for Human and Social Sciences, Spanish Council for Scientific Research, Spain.

Reviewers:

(1) Judith Mwenje, National University of Science \& Technology, Zimbabwe. (2) Qijie Gao, China Agricultural University, Beijing, P. R. China Complete Peer review History: http://www.sciencedomain.org/review-history/17982

Original Research Article

Received $16^{\text {th }}$ December 2016

Accepted $9^{\text {th }}$ January 2017

Published $28^{\text {th }}$ February 2017

\section{ABSTRACT}

The present study was conducted among the SAF -Theeramythri activity groups of Kerala across the nine coastal districts which focused on identifying the perception of the leaders and followers of the activity groups in its functioning. The benefits gained by the leader as well as the follower, short comings in the current functioning, group cohesiveness, nature of leadership existing in the groups and the future requirements were discussed in the study. The results indicated that majority of the respondents have economically benefited from SAF after joining the activity groups. The Pearson correlation indicates that the relationship between the leader and follower is high for the decision making (0.41) and least for conflict management (0.29) which has a huge impact in the effective functioning of an activity group. The Garette ranking results go in tune with correlation analysis entrusting the high interrelationship of the members and the followers of the activity groups. Moreover the study identified the constraints in the current functioning of activity groups and suggest for suitable interventions by installing effective confidence building mechanisms among group members. 
Keywords: SAF theeramythri groups; group cohesiveness; Garrette ranking; Pearsons coefficient.

\section{INTRODUCTION}

A number of persons who have common interest, who are stimulating each other, who have a common loyalty and participate in common activities can be defined as a group. The concept of group makes its real sense among the Self Help Groups (SHG) [1]. SHG is a small voluntary association of a number of persons who have common interest who are stimulating to each other, who have a common loyalty and participating in common activities. More preferably they are from the same economic background [2]. They come together for the purpose of solving their common problems through mutual help and self-help. It is felt that these group efforts can be very much adequate to improve one's fate. This brings about the necessity for organizing them in group by which they get benefit of collective decision making and collection actions for common benefits [3]. It can be said that SHG is a voluntary group formed to attain some common goals. Most of its members have similar social identity, heritage, caste or traditional occupations and come together for a common cause and manage resources for the benefit of the group members. Each SHG constitutes group leaders and members [4]. The group's performance (Fig. 1), to a large extent, is dependent on the promoting agency in the initial stages and in the long run on the resources that its members generate and accumulate for the group and on group leader play an important role. The present study focuses on the Society for Assistance to Fisherwomen (SAF) Theeramythri activity groups of Kerala to portray some valuable points regarding the leader follower relationship and their overall group coherence among the Theeramythri activity groups.

Society for Assistance to Fisherwomen (SAF) is an agency under Kerala government that works for the social and economic empowerment of fisherwomen in Kerala, through its multifarious and integrated developmental programmes. SAF was established in 2005 as a charitable society under the State Fisheries Department. SAF assists fisherwomen - both individuals and their Self Help Groups (SHGs) - to address common challenges such as livelihoods, poverty eradication and social development. The major emphasis of SAF lies in providing livelihood support to fisherwomen by promoting their selfemployment ventures under its flagship programme 'Theeramythri'. SAF, under the Theeramythri programme, provides continued handholding and mentoring to the microenterprises and livelihood ventures that were established under the earlier Tsunami Rehabilitation Programmes. Besides sustaining and strengthening the existing enterprises, each year marginalized women from fishermen community are identified, trained and assisted to start new microenterprises for income generation. Theeramythri project started in 2005 with a capital outlay of 32 crores distributed among different groups, across nine districts of Kerala. The major categories of entrepreneurial groups supported under SAF project include Garments and Textiles, Food, Fish, Coir, Supermarket and others. They mainly aim at socio economic upliftment of the fisherwomen, thereby paving way for the local development.The activity groups of SAF have now become significant for the rural development of the fisherwomen in Kerala. After the natural calamity -Tsunami, the vision of SAF through these activity groups have become one of the alternative livelihood for the fisherwomen [5]. It is clearly understood that the number of activity groups and the fisherwomen involved are increasing day by day. Today more than 5000 fisherwomen have transformed themselves into successful micro entrepreneurs under Theeramythri, earning gainful self-employment and stable incomes. Together, they operate more than 1500 microenterprises (full and part time) that do a monthly business turnover of more than Rs. 2.50 crore. The enterprises generate a profit of Rs. 60-70 lakh each month, which is utilized primarily towards their salaries and wages. In spite of their annual income they are mainly involved in these groups to meet their daily needs and activities. Rapid progress in these has now turned into an empowerment movement in all the levels among fisherwomen across Kerala [6]. Fisherwomen have become socially, economically, legally and psychologically empowered to a great extent. The role of SAF is inevitable in this huge endeavour. The trainings imparted, guidance and motivation by SAF have enabled the present scenario to these fisher women. Moreover the concept of group and the group coherence can be clearly seen among the activity group members of SAF. It can also been understood that it was this interrelationship among these group members that paved to the huge success of these activity group. Over the years the activity 


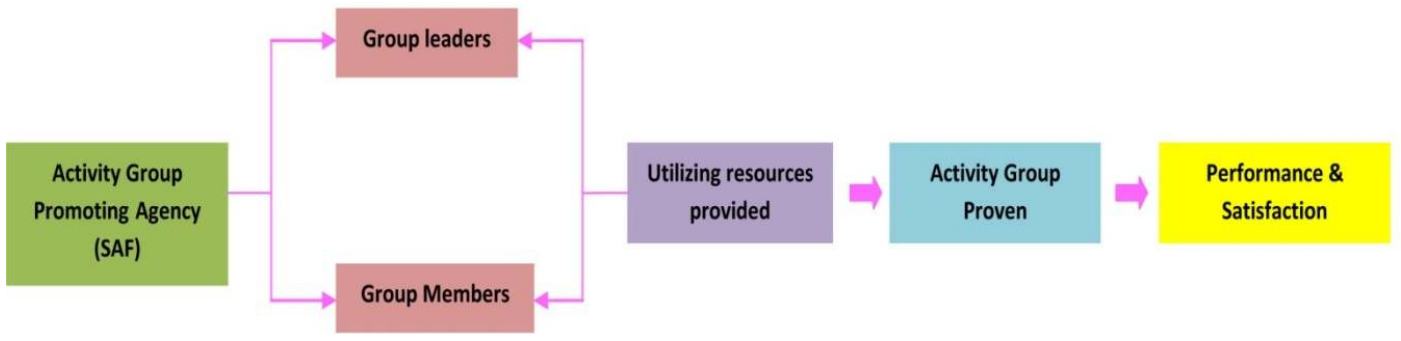

Fig. 1. Behaviour model of activity groups

groups with women involvement had led to developing alternative livelihood options and supplementary income. All these initiatives augmented the rural development of the community thereby enhancing the coastal development.

The inter-relationship of the leader and the follower has a very good impact in the success of an activity group. Leadership is a process of social influence in which one person can enlist the aid and support of others in the accomplishment of a common task. In Theeramythri groups, a leader is one who provides direction, instructions and guidance to all the members involved in the group for the purpose of achieving the success of an activity group. An effective leader will know her team members strengths, weaknesses and motivations [7]. Some of the crucial roles of the leader are developing the strategy for the team to achieve the goals, listen to the group member's feedback and also managing the day to day operations. The stake of the leader provides a crucial encouragement to all other fellow members in the group. It motivates the fellow members to work more efficiently [8]. The slight crack in this will affect the group very badly. On the other side the support, sustenance and subsistence given by the members towards the leaders also got very relevant role in the performance of an activity groups. Leaders increase group effectiveness by empowering followers to perform their job independently from the leader, highlight the importance of cooperation in performing collective tasks, and realign followers' values to create a more cohesive group. On this context, the study was conducted to analyze the perception of leader and follower across SAF activity groups of the nine coastal districts of Kerala with the following objectives:

- To identify the perception of the leader and the follower about the SAF Theeramythri activity groups.
- To evaluate the benefits gained by the leader as well as the member, short comings in the current functioning, group cohesiveness, future requirements.

- To assess the nature of leadership existing in the SAF activity group.

\section{METHODOLOGY}

The present study is under taken to assess the group dynamics and to analyse the coherence among the group members of SAF Theeramythri activity groups [9]. One of the major objectives of the study is to assess the leader - follower relationship and hence purposive random sampling technique was found appropriate for selecting the sample required for the study. Leader and one participating member from the groups of each category were selected for the study The primary data from 446 women entrepreneurs engaged in the activity groups of SAF like garments \& textiles, food, provisional store, supermarket, coir unit and others (hire service, DTP, ornamental making) etc. were collected using a well-structured questionnaire. The schedule was designed to elicit the information regarding the socio economic characteristics of the leaders and the members. The perception of the leader and the follower about the SAF Theeramythri activity groups, the benefits gained by the leader as well as the member, short comings in the current functioning, group cohesiveness, future requirements, the nature of leadership existing in the SAF activity group were the major areas covered in the schedule. The study also examined the impact of the leadership in the sustainability of the SAF activity groups. Appropriate statistical tools such as percentages, Kolmogorov Smirnov test, Garrette ranking and Pearson's rank correlation test have been carried out in the data analysis. Fig. 2 indicates the sample locations of the study. 


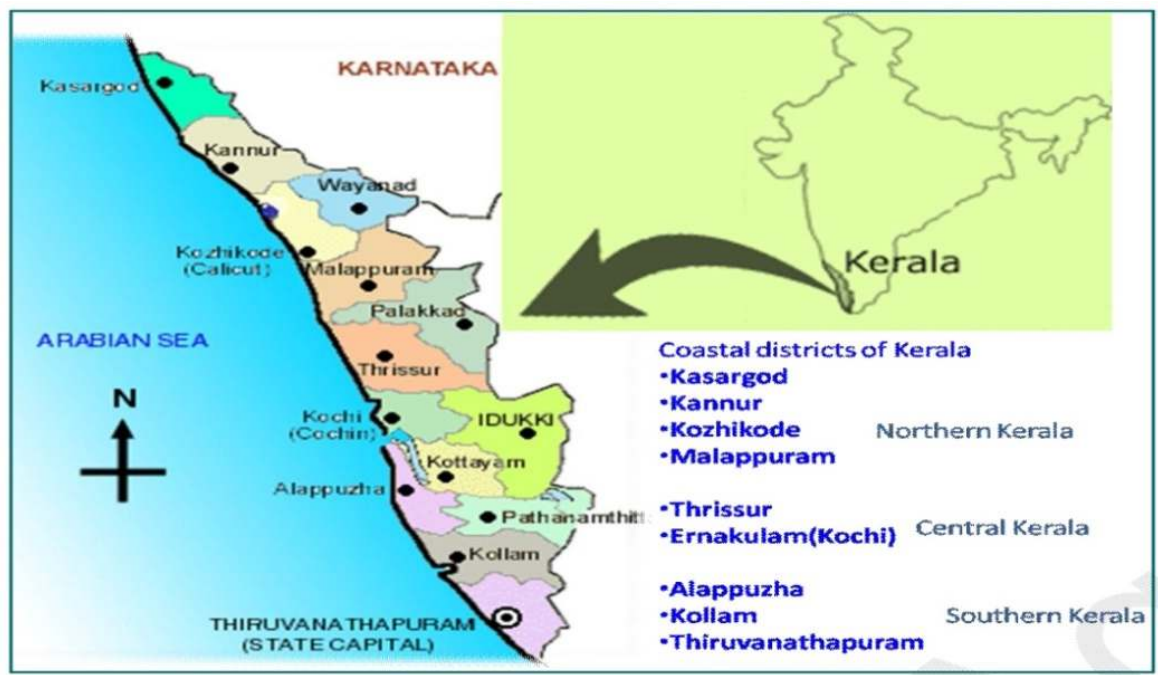

Fig. 2. Sample locations of the study

\section{RESULTS AND DISCUSSION}

\subsection{Demographic Respondents}

The demographic profile of the respondents reveals that out of 446 respondents selected for the study, $10.31 \%$ of the leaders and $8.97 \%$ of the members are below 20-30 years of age, $44.39 \%$ of the leaders and $26.91 \%$ of the members are in between 31 - 40 years. Majority of the activity group have young people as their leaders leading to one of the best reasons for the active group participation. About $26.91 \%$ and $33.63 \%$ of leaders and members belong to the age group of $41-50$ years. Most of the members belong to this category of age. $18.39 \%$ and $30.49 \%$ of the leaders and members are of above 50years of age. Hence women of all age groups are very effectively participating in the group activities of SAF. The painful hazards suffered by them throughout these years are the major reason of these fisher women to engage in this activity group under this age. Education is not a matter of concern to be the members of the group. $47.53 \%$ of the members have basic primary level education, $33.63 \%$ are having Matriculation as their qualification. Very few members of self-help groups have their qualification up to Plus Two(10.76\%) and Graduation level (8.07\%). Whereas in leaders, majority of them have Matriculation level of education(68.18\%).Only $22.42 \%$ are below matriculation level, $7.17 \%$ corresponds to Plus Two level and $2.24 \%$ to Degree level respectively. The Table 1 shows the demographic profile of the respondents.
Table 1. Demographic profile of respondents

\begin{tabular}{lll}
\hline \multicolumn{3}{c}{ Age - wise classification of respondents } \\
\hline \multirow{2}{*}{ Age } & \multicolumn{2}{c}{ Respondents } \\
\cline { 2 - 3 } & Leader & Member \\
\hline $20-30$ yrs & $46(10.31)$ & $40(8.97)$ \\
$31-40$ yrs & $198(44.39)$ & $120(26.91)$ \\
$41-50$ yrs & $120(26.91)$ & $150(33.63)$ \\
Above 50 yrs & $82(18.39)$ & $136(30.49)$ \\
Total & 446 & 446 \\
\hline \multicolumn{3}{r}{ Education-wise classification of } \\
\multicolumn{3}{c}{ respondents } \\
\hline Qualification & \multicolumn{2}{c}{ Respondents } \\
\cline { 2 - 3 } & Leader & Member \\
\hline Below 10 & $100(22.42)$ & $212(47.53)$ \\
SSLC & $304(68.16)$ & $150(33.63)$ \\
Plus two & $32(7.17)$ & $48(10.76)$ \\
Degree & $10(2.24)$ & $36(8.07)$ \\
Total & 446 & 446 \\
\hline
\end{tabular}

\subsection{Benefits Gained}

The vital function of the SAF project is to provide access to credit in the context of poverty reduction and women's empowerment. With the aim to meet the Millennium development Goals and microfinance programmes, role in supporting it, there has been an increasing expectation on their impact on women empowerment. However, the perception and expectations of the members of the activity groups vary from person to person. In order to find the benefits gained by the leaders and members after joining the activity group, the sample respondents were categorized into five ranks that is to say 1-Highly dissatisfied, 2Dissatisfied, 3-Moderate,4-Satisfied and 5-Highly 
Satisfied. The ranking was done on the basis of the scores of each respondent for each impact. Altogether there are six categories of impacts and there are five ranks. The number of respondents for each impact with ranks 1, 2, 3, 4 and 5 is arranged in rows and the corresponding row and $D$ value is applied by using the Kolmogorov - Smirnov Test (Table 2).

Table 2. Benefits gained by respondents

\begin{tabular}{llll}
\hline $\begin{array}{l}\text { SI. } \\
\text { no }\end{array}$ & $\begin{array}{l}\text { Benefits } \\
\text { gained }\end{array}$ & Leader & Member \\
\hline 1 & Training and & 22.40 & 25.68 \\
& support & (IV) & (IV) \\
2 & Motivation/ & 11.58 & 19.02 \\
& Leadership & (V) & (V) \\
3 & Accomplishments/ & 45.30 & 39.84 \\
& Satisfaction & (II) & (II) \\
4 & Economic benefits & 68.20 & 58.64 \\
& & (I) & (I) \\
5 & Social upliftment & 33.64 & 32.04 \\
& & (III) & (III) \\
6 & Interaction with & 8.54 & 10.60 \\
& SAF stakeholders & (VI) & (VI) \\
\hline \multicolumn{4}{c}{ Figures in parenthesis indicates rank }
\end{tabular}

The results revealed that the respondents felt that they have gained a lot of benefits from SAF after involving in the activity groups. Majority of leaders and members have highly economically benefited from joining SAF. This could be understood by the first rank they have given for the economic benefit (I, 68.20, 58.64). On the other side accomplishments and satisfaction gained by the respondents were the next greatest achievements of the respondents (II, 45.30, 39.84) followed by social upliftment (III, 33.64, 32.04), Training and support (IV, 22.40, 25.68), Motivation and leadership (V, $11.58,19.02)$ and interaction with the stake holders (VI, 8.54, 10.60). It has also been understood that the Kolmogorov -Smirnov test shows a valid significant difference in the ranking of all categories of impact among the members. The respondents have gained some sort of increased benefits after involving in these groups. The economic levels of the leaders as well as the followers have greatly increased after joining in the SAF activity groups. They become self-sufficient to meet their daily needs and even to save some for their future. They themselves own the job. The better time management of tasks, low work pressure, previous experiences, skills and trainings imparted has influenced them in achieving all the so called benefits after involving in SAF activity groups.

\subsection{Group Cohesiveness / Group Atmosphere and Support from Members}

Correlation analyses using the Pearson correlation coefficient have been carried out in order to understand the relationship between the leader and the follower. The study clearly reinforces the relation between the leaders' group atmosphere and the support from members and also the group cohesiveness of the members. The respondents were given nine parameters under each head- group atmosphere and support from members (leaders) and group cohesiveness (members). Their response is as given scores: 1- Highly Dissatisfied, 2Dissatisfied, 3-Moderate, 4- Satisfied, 5- Highly Satisfied. The results of the correlation analysis are given in the Table 3. For assuring the correlation analysis results Garrette ranking have been done for the leader and follower and the results are depicted in Table 4.

The Pearson correlation indicates that the relationship between the leader and follower is high for the decision making power (0.41) followed by sharing of dividend (0.39), frequency of meetings (0.38), Conflict management (0.29), Sharing of responsibilities (0.27), Financial appropriation and management (0.27), Managing resources (0.27), absenteeism and management (0.27). All the parameters have got strong relationship between each other. Decision making power of the leader as well as the follower has got the high impact for the effective functioning of activity groups. The group atmosphere and support from members for the leader is highly depend on the group cohesiveness of the followers. Further the group members are encouraged to share their thoughts, democratic leadership can leader to better ideas and more creative solutions to problems. Group members also feel more involved and committed to group activities, making them more likely to care about the end results. Research on leadership styles has also shown that democratic leadership leads to higher productivity among group members. The members of the group felt that the leadership style i.e., democratic which is selflessness connotes serving the purpose of others before serving themselves. Members of the group always want their needs to be met first before the leaders meet up with their needs. To some extent SAF and the group leaders was very successful in considering the needs of the members of the activity groups. 
Table 3. Correlation analysis of leader and follower

\begin{tabular}{|c|c|c|c|c|c|c|c|c|}
\hline Follower & $\begin{array}{l}\text { Decision } \\
\text { making } \\
\text { power }\end{array}$ & $\begin{array}{l}\text { Frequency of } \\
\text { meeting }\end{array}$ & $\begin{array}{l}\text { Sharing of } \\
\text { dividend }\end{array}$ & $\begin{array}{l}\text { Financial } \\
\text { appropriation } \\
\text { and } \\
\text { management }\end{array}$ & $\begin{array}{l}\text { Sharing of } \\
\text { responsibilities }\end{array}$ & $\begin{array}{l}\text { Managing } \\
\text { resources }\end{array}$ & $\begin{array}{l}\text { Conflict } \\
\text { management }\end{array}$ & $\begin{array}{l}\text { Absenteeism } \\
\text { and } \\
\text { management }\end{array}$ \\
\hline Decision making power & 0.41 & 0.18 & 0.29 & 0.21 & 0.28 & 0.26 & 0.24 & 0.23 \\
\hline Frequency of meeting & 0.23 & 0.38 & 0.17 & 0.13 & 0.23 & 0.17 & 0.16 & 0.23 \\
\hline Sharing of dividend & 0.22 & 0.13 & 0.39 & 0.29 & 0.23 & 0.24 & 0.16 & 0.11 \\
\hline $\begin{array}{l}\text { Financial appropriation } \\
\text { and management }\end{array}$ & 0.32 & 0.09 & 0.30 & 0.27 & 0.30 & 0.25 & 0.22 & 0.08 \\
\hline Sharing of responsibilities & 0.29 & 0.14 & 0.23 & 0.27 & 0.26 & 0.23 & 0.25 & 0.21 \\
\hline Managing resources & 0.20 & 0.17 & 0.26 & 0.22 & 0.31 & 0.27 & 0.24 & 0.20 \\
\hline Conflict management & 0.13 & 0.06 & 0.17 & 0.20 & 0.23 & 0.18 & 0.29 & 0.15 \\
\hline $\begin{array}{l}\text { Absenteeism and } \\
\text { management }\end{array}$ & 0.25 & 0.21 & 0.19 & 0.19 & 0.26 & 0.27 & 0.23 & 0.27 \\
\hline
\end{tabular}


Table 4. Garrett ranking between leader and follower

\begin{tabular}{lllll}
\hline Parameters & Leader & Rank & Follower & Rank \\
\hline Decision making process & 81.63 & I & 79.90 & I \\
Sharing of dividend & 79.46 & II & 79.52 & II \\
Sharing of responsibilities & 79.28 & III & 78.62 & III \\
Conflict management & 76.74 & IV & 76.32 & IV \\
Absenteeism and management & 76.64 & V & 74.51 & V \\
Frequency of meeting & 73.51 & VI & 74.13 & VI \\
Managing resources & 72.93 & VII & 73.41 & VII \\
Financial appropriation & 71.84 & VIII & 72.12 & VIII \\
\hline
\end{tabular}

The Garrett ranking results reinforce the correlation analysis. From Table 4 it is clearly understood that 81.63 per cent of the leaders and 79.90 percent followers choose decision making process as the first criteria as their perception for the group cohesiveness and support. It emancipates the strong bond between them in the most appropriate manner.79.46 per cent and 79.52 per cent of leaders and followers choose sharing of responsibilities as the second. Conflict management stands the third, a majority of 76.74 percent of leaders and 76.32 percent of members support for the same. Absenteeism and management, Frequency of meetings, Managing resources and financial appropriation were followed by the same with the corresponding percentages as shown in the above table.

One of the other major finding of the study is the inter-bond relationship of the leader and the follower. A small crack in this relation will definitely leads to the closure of the activity groups. All these elucidate the fact that a part from the financial aspects the groups should work in the same with all the cooperation and effort should be made to make the group viable i.e., Leaders and followers should have common interest stimulating to each other with a common loyalty and should participate in all the activities respecting each other. For this, there should be more training programmes for the leader and the followers for motivating them to build a sustainable relationship between the leader and the follower for their success in future.

\subsection{Constraints in the Current Functioning}

Some of the main constraints faced by the leaders were identified and are presented in Fig. 3 . The main problem faced by the members was due to inadequate funds i.e., it is due to the inadequate funds that the capital for the group activities is defamed. The lack of a brand was one of the other issues faced by the groups. Most of the provisional outlets, supermarkets etc., get demolished due to the shortage of a brand name. Lack of skill up gradation and the funds spent for the other activities were the next two major shortcomings of the future. Raw material shortage, conflict among members, inadequate operational space, delay in disbursal, absenteeism, quality issues, seasonality of business etc., were also found as the major shortcomings for the current functioning of activity groups. The Fig. 3 shows a clear picture of the short comings in the current functioning.

Fig revealed that 78.95 percent of the leaders are facing the difficulty of the inadequate fund provided by SAF. Due to this financial deficit the leaders are trawling behind to meet the needs of the activity groups.75.01 percent respondent that lack of branding was their major constraint. Most of the supermarkets and the fish activity groups are facing the huge burden of a perfect brand.72.1 percent of them opined that lack of skill up gradation was the other major constraint. It could be understood that the garments and textiles groups are the most who are in need of the skill up gradation. Most of these activity groups include those who are not having the subsistent skill to run their group. These lack of skill up gradation diminishes the overall group performance. Fund spent on other issue was the major constraint of 70 percent of the respondents. The other constraints such as absenteeism (68 percent), quality issues (67.54 percent), raw material shortage (60.05 percent), seasonality of business (58.33 percent), technical support from SAF (52.33 percent), competition from market (50.21 percent), conflicts among members (48.32 percent), delay in disbursal (45.63 percent), lack of institutional linkages (42.35 percent) have also got serious impact in the functioning of an activity group. Suitable measures have to be undertaken to overcome the constraints affecting the efficient functioning of activity group. There should be 


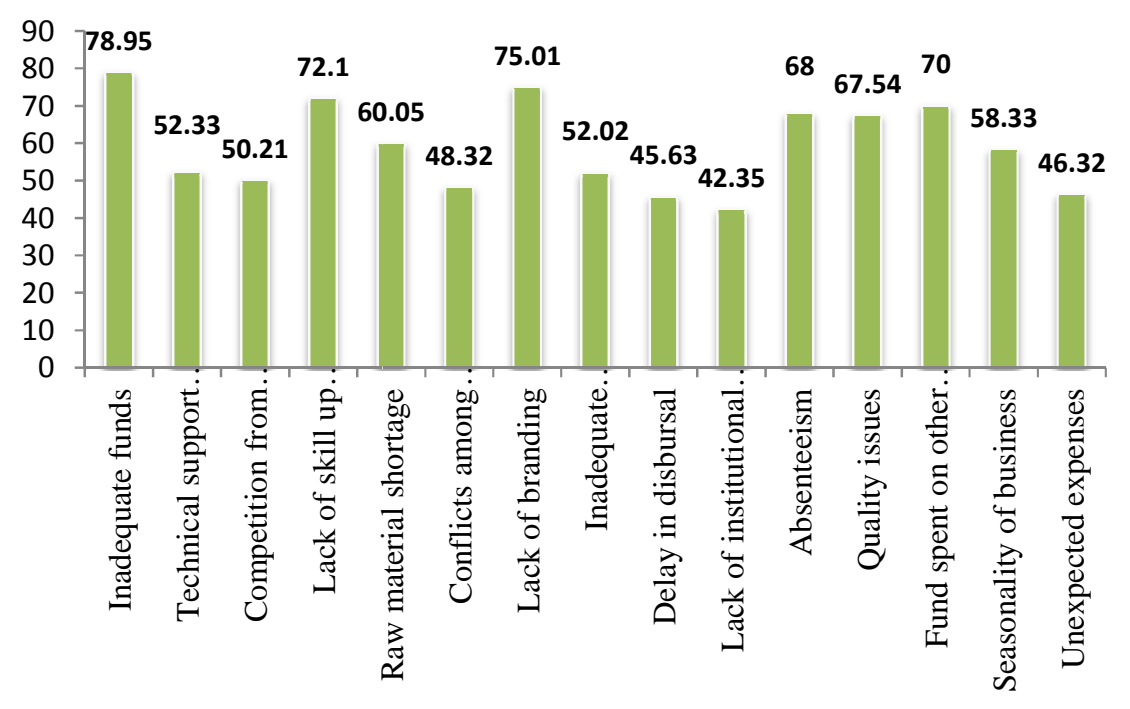

Fig. 3. Constraints in the current functioning

more focus on the product development and the value addition, branding, fund sourcing, allocation of funds and disbursement, monitoring and evaluation, asset creation, enterprise management, availability of raw material and follow up studies. Thereby the existing scenario of constraints could be reduced to a great extent.

\section{CONCLUSION}

Good leaders are known to be selfless. Leaders of the groups were selected by the members of the groups depending on their leadership qualities and the opportunity to lead them, was bestowed with rotations among the group members. High respect for group goals and ideas can be seen in the activity groups which needs integrity among leaderships. Another important characteristic of leaders of Theeramythri groups are their ability to help group members and realign their personal values according to their leader's vision and goals, which creates strong values of internalization, cooperation, and congruence among followers. As a result, there exist strongly shared vision developed in the group, with improved cohesiveness. Shared vision and strong group identity also help leaders further to empower group members to accomplish their goals without closely monitoring group members' work process. This high degree of collective identification may enhance group cohesiveness among team members. Leaders arouse the affiliation motive among followers, which drives their followers to become more cohesive and perform effectively. Strong group cohesiveness could give group members a sense of where they need to direct their efforts to materialize their common goals. As such, we expected to find a positive association between leadership and group members' cohesion. Moreover, it was found that the group members prioritise the personal needs over the leader's needs. Members are encouraged to share their thoughts; so that leaders can lead to better ideas and more creative solutions to problems. Group members feel more involved and committed to group activities, making them more likely to care about the end results. Moreover the support, sustenance and subsistence given by the members towards the leaders also got very relevant role in the performance of an activity groups. Leaders increase group effectiveness by empowering followers to perform their job independently from the leader, highlighting the importance of cooperation in performing collective tasks, and realign followers' values to create a more cohesive group.

\section{COMPETING INTERESTS}

Authors have declared that no competing interests exist.

\section{REFERENCES}

1. Ojha SN, Sharma Arpita, Shyam S. Salim. Institution building process of a fisherwomen society. In: Women Empowerment in Fisheries. Narendra Publishing House, New Delhi. 2005;249260. 
2. Dubey Kiran, Kohli MP. An overview on the contribution women in Asian fisheries. Proceedings; 2001.

3. Anjugam M, Ramasamy C. Determinants of women's participation in self help group led micro finance programme in Tamil Nadu, Agricultural Economics Research Review. 2007;20:2.

4. Sathiadhas R, Ashaletha S, Sadanandan $S$, Joseph Raj Y. Women workers in the post-harvest marine fisheries sector of Kerala: Socio-economic profile. Fishing Chimes. 2003;23(2):31-35.

5. Shyam S. Salim, Geetha R. Empowerment of fisherwomen in Kerala- An assessment. Indian Journal of Fisheries. 2013;60(3): 73-80.
6. Vipin Kumar VP, Shyam S. Salim, Deshmunh VD, Raje SG, Sawant Paramita Banerjee. Success case studies of women mobilisation in marine fisheries sector of Maharashtra. Nature. 2013;2(6):21-25.

7. Paola Ballon. A structural model of female empowerment. OPHI, University of Oxford; 2012.

8. The Economic and Social Council 1997. Report on Gender Mainstreaming.

9. Shyam S. Salim, Reeja Fernandez, Athira NR. Performance appraisal of Theeramythri Initiatives in Kerala: Benefit monitoring assessment and visioning for the future. Technical Report. ICAR-Central Marine Fisheries Research Institute, Kochi, Kochi. 2016;252.

(0) 2017 Salim et al.; This is an Open Access article distributed under the terms of the Creative Commons Attribution License (http://creativecommons.org/licenses/by/4.0), which permits unrestricted use, distribution, and reproduction in any medium, provided the original work is properly cited.

Peer-review history:

The peer review history for this paper can be accessed here: http://sciencedomain.org/review-history/17982 